\title{
Genetic prevention of lymphoma in p53 knockout mice allows the early development of p53-related sarcomas
}

\author{
Lorena Landuzzi ${ }^{1,2}$, Marianna L. Ianzano ${ }^{3}$, Giordano Nicoletti ${ }^{1,2}$, Arianna Palladini ${ }^{3}$, \\ Valentina Grosso ${ }^{3}$, Dario Ranieri' ${ }^{3}$ Massimiliano Dall'Ora ${ }^{3}$, Elena Raschi ${ }^{3}$, \\ Roberta Laranga ${ }^{3}$, Marco Gambarotti ${ }^{4}$, Piero Picci $^{1}$, Carla De Giovanni ${ }^{3}$, \\ Patrizia Nanni ${ }^{3}$, Pier-Luigi Lollini ${ }^{3}$ \\ ${ }^{1}$ Laboratory of Experimental Oncology, Rizzoli Orthopedic Institute, Bologna, Italy \\ ${ }^{2}$ PROMETEO Laboratory, STB, RIT Department, Rizzoli Orthopedic Institute, Bologna, Italy \\ ${ }^{3}$ Laboratory of Immunology and Biology of Metastasis, Department of Experimental, Diagnostic and Specialty Medicine, \\ University of Bologna, Bologna Italy \\ ${ }^{4}$ Anatomy and Pathological Histology, Rizzoli Orthopedic Institute, Bologna, Italy \\ Correspondence to: \\ Patrizia Nanni, e-mail: patrizia.nanni@unibo.it \\ Keywords: p53-KO mice, Rag2KO/II2rgKO mice, lymphoma, hemangiosarcoma, osteosarcoma \\ Received: August 04, 2014 \\ Accepted: October 27, 2014 \\ Published: November 18, 2014
}

\section{ABSTRACT}

Homozygous knockout of p53 in mice leads to early mortality from lymphoma, with almost complete penetrance, thus hampering studies of other tumor histotypes related to p53 alterations. To avoid Iymphoma development, we crossed p53 knockout mice (BALB-p53 mice) with alymphocytic BALB/C Rag2-/-;Il2rg-/(RGKO) mice. We compared the tumor spectrum of homozygous (BALB-p53-/-) and heterozygous (BALB-p53 $3^{+/-}$) mice with alymphocytic mice (RGKO-p53 ${ }^{-1-}$ and RGKO-p53 ${ }^{+/-}$). Lymphoma incidence in BALB-p53-/- mice exceeded $80 \%$, whereas in RGKO-p53-/- it was strongly reduced. The prevalent tumor of RGKO-p53-/- mice was hemangiosarcoma (incidence over $65 \%$ in both sexes, mean latency 18 weeks), other tumors included soft tissue sarcomas (incidence $\sim 10 \%$ ), lung and mammary carcinomas. Tumor spectrum changes occurred also in p53 heterozygotes, in which lymphomas are relatively rare ( 20\%). RGKO-p53 ${ }^{+/-}$had an increased incidence of hemangiosarcomas, reaching $\sim 30 \%$, and females had an increased incidence of osteosarcomas, reaching $\sim 20 \%$. Osteosarcomas shared with the corresponding human tumors the involvement of limbs and a high metastatic ability, mainly to the lungs. Specific alterations in the expression of p53-related genes (p16Ink4a, p19Arf, p15Ink4b, p21Cip1) were observed. Genetic prevention of lymphoma in p53 knockout mice led to new models of sarcoma development, available for studies on hemangiosarcoma and osteosarcoma onset and metastatization.

\section{INTRODUCTION}

The expression of the tumor suppressor gene p53 is altered by mutation and other mechanisms in a large proportion and in a wide variety of human cancers $[1,2]$.

p53 knockout mice are a precious tool to investigate the mechanisms of carcinogenesis in the absence of p53. However, p53 knockout mice are prone to the early development of lymphomas, in particular of thymic origin [3-5], hence the study of other solid tumors is greatly hampered in these mice.
This is a general problem in mice harboring cancer syndromes. Early onset and lethality of a given tumor type can preempt the study of other tumors arising later in life. It is a problem mostly unsolvable, even though empirical solutions can be found in some instances by changing the genetic background, or through direct or indirect modifications of the gene of interest, for example using tissue-specific Cre-lox systems [4].

In the case of $\mathrm{p} 53$, variations in tumor spectrum were obtained either using mutant p53 genes with gain of function properties [6-9] or through conditional 
inactivation of p53 in specific tissues [4, 10-14]. Gain of function mutants are certainly informative for what concerns the corresponding human mutations, but not for those conditions, such as the Li-Fraumeni syndrome, in which biallelic losses are frequent lesions [4]. On the other hand, inactivation of p53 in prespecified tissues leaves open the question of which tumors could result from an organism-wide lack of p53.

For what concerns the predominant lymphoma of p53 knockout mice, the cell population at risk of neoplastic transformation, i.e. lymphocytes, is not indispensable for life, at least under sterile conditions, and various alymphocytic mouse lines were obtained through genetic manipulation. Therefore, we reasoned that cross-breeding of p53 knockout mice with alymphocytic mice could avoid lymphoma development. We show here that p53 knockout mice crossed with $\mathrm{Rag} 2^{-/} ; \mathrm{Il}_{2} \mathrm{rg}^{-/-}$mice (RGKO-p53 ${ }^{-/}$ mice), which lack T, B and NK cells [15], had a strong impairment of lymphoma development, thus allowing the study of solid tumors, mainly sarcomas, caused by the lack of $\mathrm{p} 53$.

\section{RESULTS}

\section{Tumor incidence and survival of alymphocytic p53 knockout mice}

BALB-p53 ${ }^{+/-}$mice were crossed with Rag2 $2^{-/-} ; \mathrm{Il}_{2} \mathrm{rg}^{-/}$ (RGKO) mice. Knockout of Rag2 (recombinase activating gene 2) prevents V(D)J recombination, and knockout of Il2rg (common gamma chain of IL-2, IL-4, IL-7, IL-9, IL-15 and IL-21 receptors) blocks signal transduction by cytokine receptors. RGKO mice display a complete absence of mature T, B and NK cells [15].

$\mathrm{Rag}^{+/-}, \mathrm{Il} 2 \mathrm{rg}^{+/-}, \mathrm{p} 53^{+/-}$PCR-selected female mice of the F1 generation were backcrossed with male RGKO mice to obtain and select the F2 generation with homozygous RGKO and $\mathrm{p} 53^{+/-}$genotype (Fig. 1). F3 generation was obtained by crossing F2 RGKO-p53 $3^{+-}$ male and female mice. As expected, a quarter of the progeny had a RGKO-p53 $3^{-/}$genotype.

All $\mathrm{p} 53^{-/-}$mice developed progressive tumors by 30 weeks of age (Fig. 2A). Tumor onset was slightly, but significantly, delayed in RGKO-p53 mice: BALB-p53 ${ }^{-1-}$ mice had a median tumor-free survival time of 16 weeks, while RGKO-p53 ${ }^{-1-}$ mice had a median of 19.5 weeks, however, after 20 weeks of age, the tumor-free survival curves overlapped.

\section{Prevention of lymphoma development}

More then three quarters of BALB-p53 ${ }^{-/}$mice developed lymphomas, mostly of thymic origin. A minority of mice developed sarcomas or carcinomas (Fig. 2B), frequently in combination with lymphoid tumors.
The incidence of lymphomas in RGKO-p53-mice was strongly reduced and became a sporadic event, possibly resulting from the neoplastic transformation of immature precursors (see below).

Prevention of lymphoma allowed the onset of a variety of other tumor histotypes, mostly sarcomas (Fig 2B). Over two-thirds of both female and male RGKO-p53 $3^{--}$mice developed spontaneous malignant vascular tumors, here collectively indicated as hemangiosarcomas, in skin, muscles, liver, lungs, peritoneal membranes, intestine, spleen and genito-urinary tract. Most vascular tumors of RGKO-p53 ${ }^{-/}$mice showed the features of aggressive angiosarcomas (Fig. 3 A-C) expressing endothelial markers, such as VEGF-R2, CD31 and CD146, as determined by FACS analysis (Fig. 4). About half of mice carrying hemangiosarcomas had a multifocal or disseminated disease. The general tumor burden (number of tumor sites) of BALB-p53 $3^{-/-}$and RGKO-p53 $3^{-/}$mice were similar (median 2, range $1-8$, and median 2, range 1-11, respectively). However the proportion of mice with multiple tumor histotypes was significantly increased in RGKO-p53 $3^{-1-}$ mice (Fig. 5).

Tumor-free survival curves of individual tumor histotypes showed that lymphoma-free survival and hemangiosarcoma-free survival differed significantly

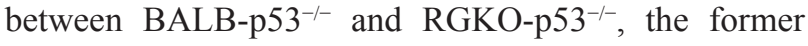
developing early lymphomas and only few hemangiosarcomas and the latter showing the opposite (Fig. 6A). Tumor-free survival curves for osteosarcoma, soft tissue sarcoma and mammary carcinoma did not differ significantly between the two strains.

Interestingly, in RGKO-p53-/- mice, the global incidence of carcinomas (34\%) was significantly lower than that of sarcomas $(82 \%)$, thus suggesting that neoplastic transformation of epithelial cells was slower than that of mesenchymal cells, or required additional somatic events.

Finally we addressed the question of the origin of lymphomas in RGKO-p53 $3^{-/}$mice. It must be kept in mind that these "alymphocytic" mice actually lack lymphocytes with a rearranged antigen receptor, but bone marrow lymphopoiesis and migration proceed normally. The rare lymphomas of RGKO-p53 ${ }^{-/-}$mice arose predominantly in the thymus. One case studied by flow cytometry consisted of blast cells with large forward and side scatter and an immature single-positive (ISP)-like phenotype (CD45R/ $\mathrm{B}_{220}{ }^{\mathrm{dim}}, \mathrm{CD}^{-}, \mathrm{CD}^{-}, \mathrm{CD}^{+}$) [16-19]. The residual incidence of lymphomas in RGKO-p $53^{--1}$ mice suggests that lymphomas of $\mathrm{p} 53^{-/-}$mice should be re-examined to assess the role of p53 before and after rearrangement.

\section{Tumors of p53 heterozygous mice}

The breeding scheme adopted to obtain RGKO-p53 $3^{-1-}$ mice gave us the opportunity to study also $\mathrm{p} 53^{+/-}$heterozygotes, in which tumor development was 


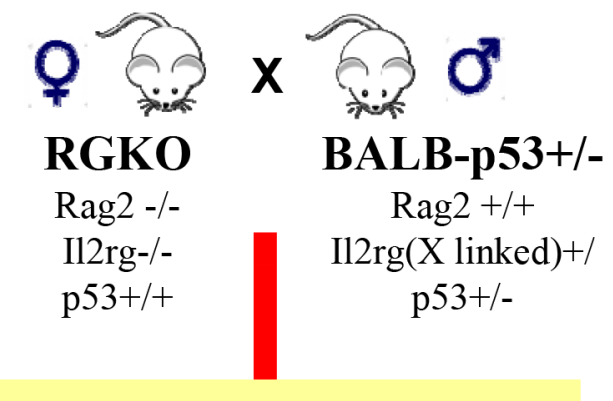

\section{PCR selected F1 generation}
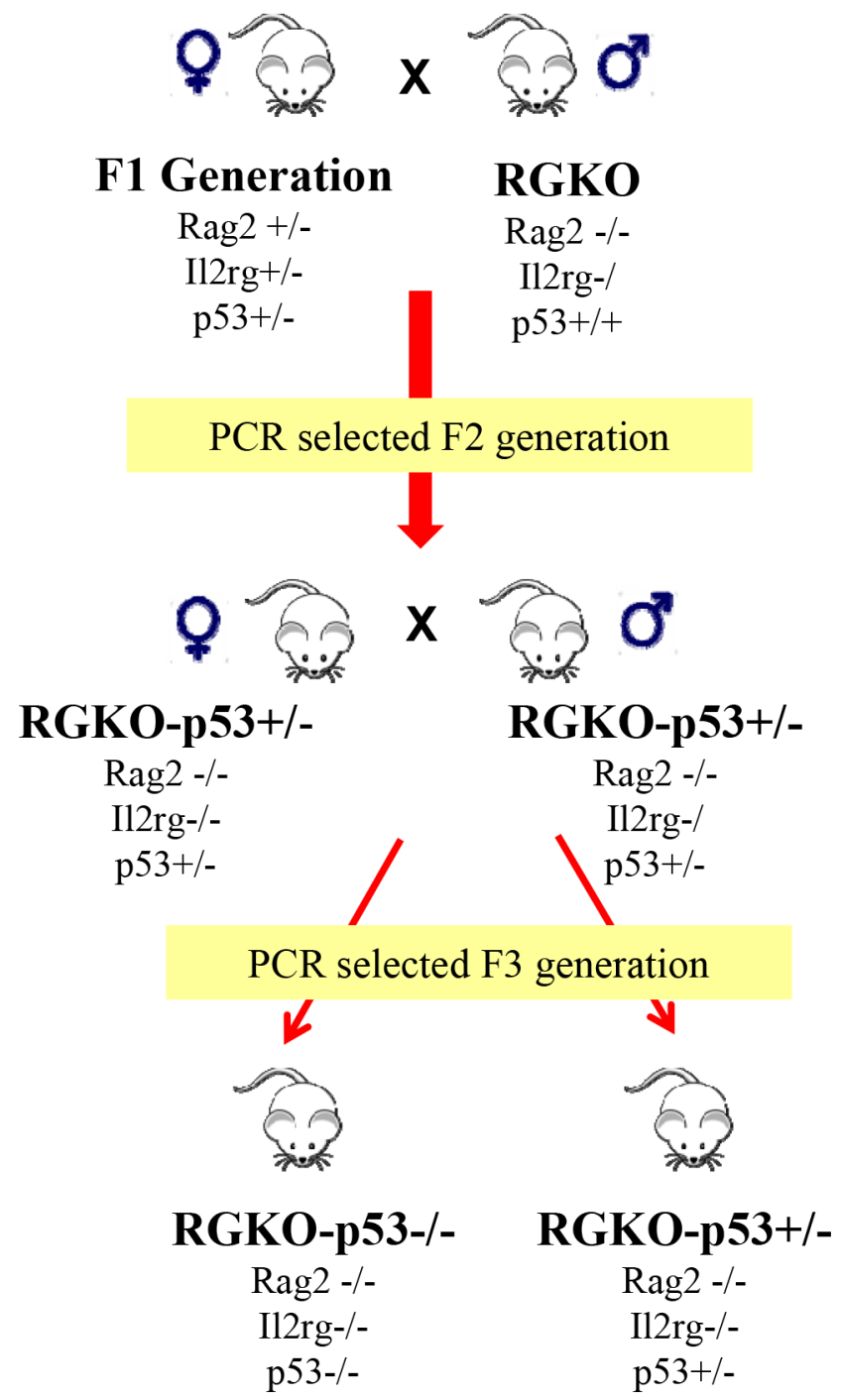

Figure 1: Obtainment of alymphocytic p53 knockout mice. Male BALB-p53 ${ }^{+/}$mice were crossed with female Rag2 $2^{-/-}$; Il $2 \mathrm{rg}^{-/}$ (RGKO) mice to obtain the F1 generation, the progeny was genotyped by PCR. Taking advantage of the X-linked Il2rg gene, female F1 mice carrying the genotype indicated in figure were backcrossed with male RGKO mice. At the F2 generation PCR genotyping allowed to select RGKO-p53 $3^{+-}$male and female mice that were backcrossed to obtain, from the F3 generation, female and male RGKO mice with homozygous or heterozygous 553 ablation, as determined by PCR genotyping. 
A

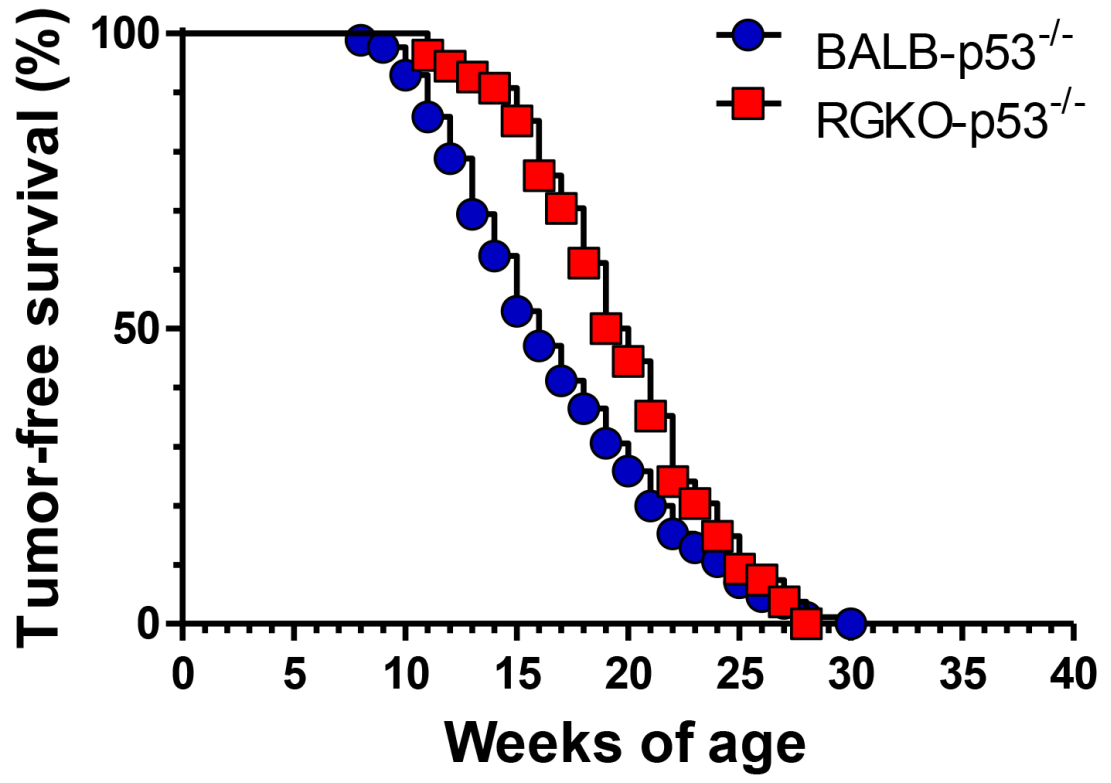

B

ఇ Lymphoma

II Hemangiosarcoma

$\square$ Soft tissue sarcoma

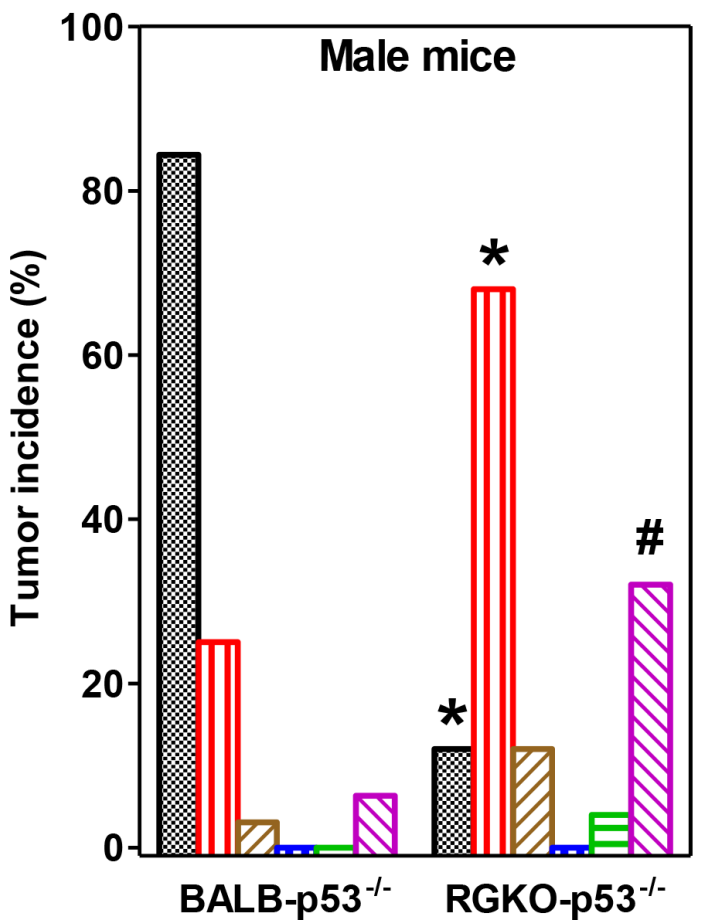

Q Osteosarcoma

Mammary carcinoma

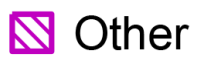

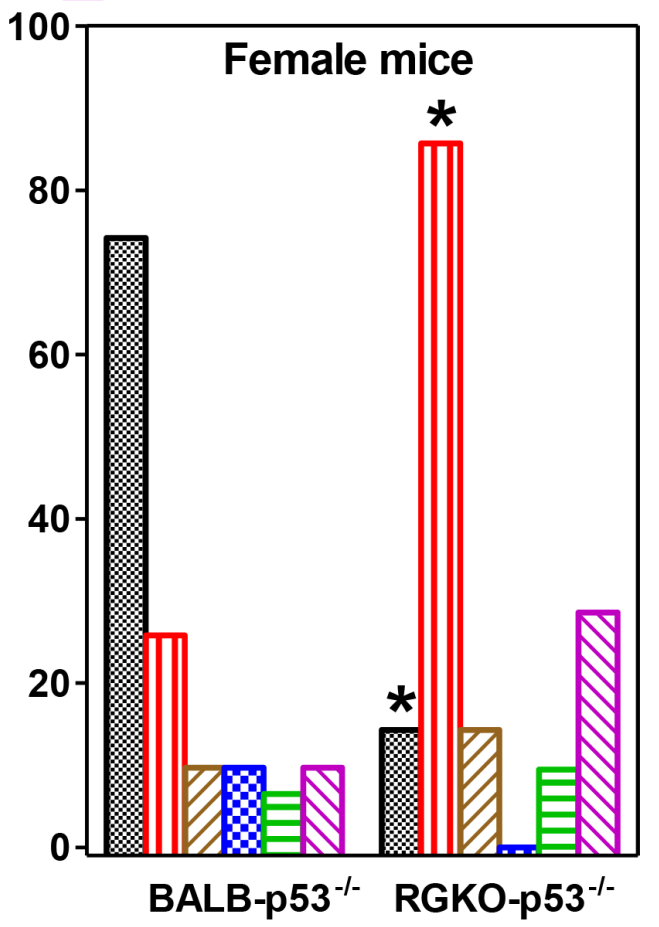

Figure 2: Tumor-free survival and tumor histotype incidence in homozygous p53 knockout mice. (A) Kaplan-Meier tumor-free survival curves of BALB-p53 $3^{-/}$( 85 mice) and RGKO-p53 $3^{-/}$mice (54 mice) were significantly different by the logrank MantelHaenszel test, $p<0.01$. (B) Tumor histotype frequencies in BALB-p53 $3^{-/-}$and RGKO-p53 $3^{-/-}$mice. Alymphocytic RGKO-p53 $3^{-/-}$mice showed significantly reduced lymphoma incidence and significantly increased hemangiosarcoma onset compared to BALB-p53 $3^{-/-}$mice $(*=p<0.01$, $\chi^{2}$ analysis; male BALB $n=32$, male RGKO $n=25$; female BALB $n=31$, female RGKO $n=21$ ). The category "Other" included tumors of the lungs, genitourinary tract, salivary glands, kidneys and liver, and its incidence in males was significantly higher in RGKO-p53 ${ }^{-/}$compared

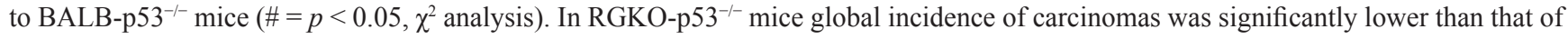
sarcomas (34\% vs. 82\%, respectively, $p<0.01$ by $\chi^{2}$ analysis). Mice showing multiple primary tumors were counted in each tumor type. 

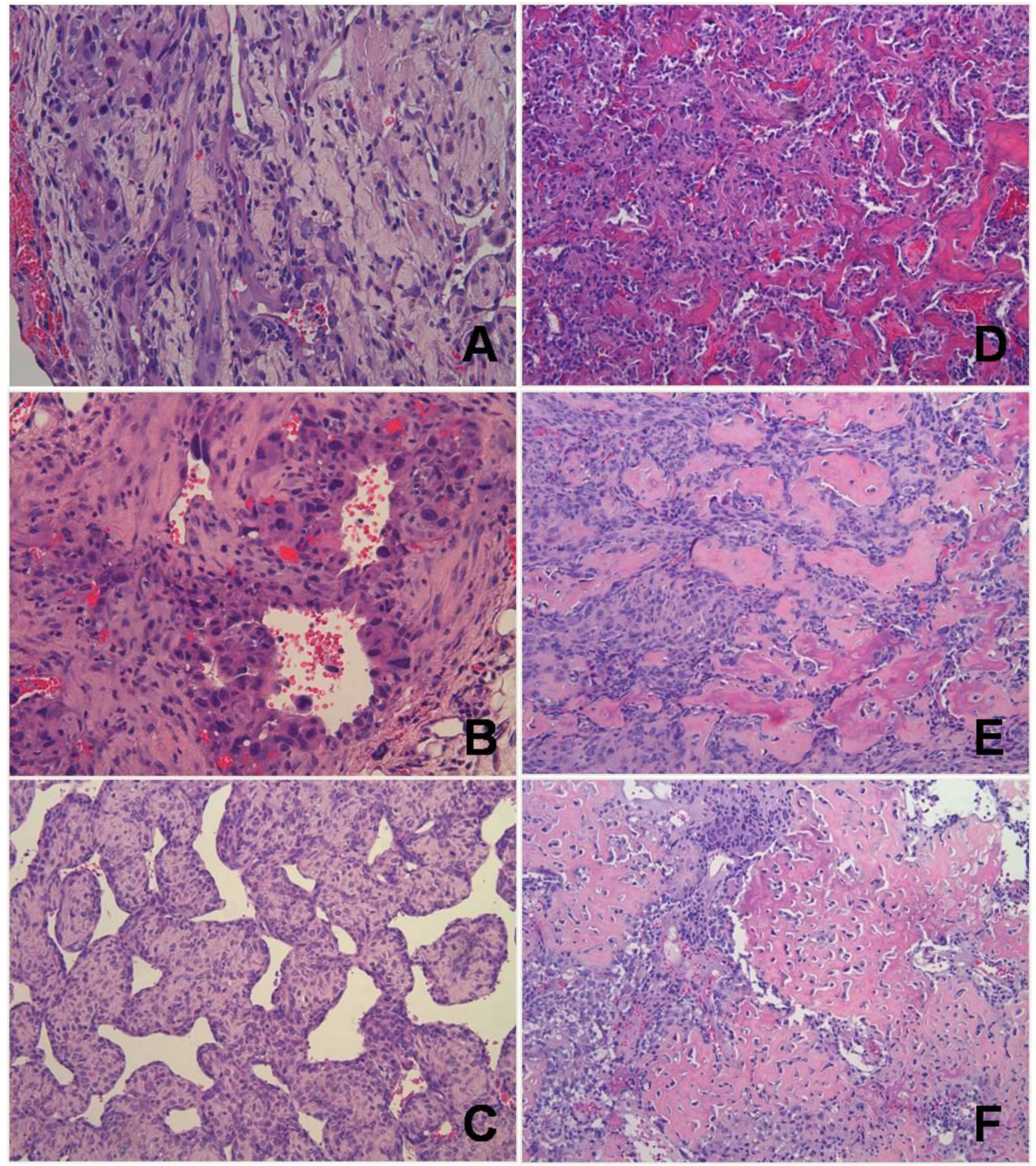

Figure 3: Representative histology of vascular and perivascular tumors of RGKO-p53 ${ }^{-/-}$mice and of osteosarcomas of

RGKO-p53 ${ }^{+/}$mice. (A) Soft tissue lesion of the genito-urinary tract showing a tumor of vascular origin with features of an angiosarcoma; mHS-1 cell line was derived from this tumor. (B) Soft tissue lesion of the cervico-nuchal region with malignant cells surrounding vessels that suggest a diagnosis of angiosarcoma; mHS-2 cell line was established from this tumor. (C) Soft tissue lesion of the right forelimb showing an histological pattern of hemangiopericytoma/solitary fibrous tumor. (D) Ossified mass of the right hind limb, osteosarcoma grade 3. The osteosarcoma cell line mOS-1 was derived from this tumor. (E) Ossified mass of the left hind limb, osteosarcoma grade 4. The osteosarcoma cell line mOS-2 was derived from this tumor. (F) Ossified mass of the right hind limb, osteosarcoma grade 4, showing presence of lau-like cells. All pictures: hematoxylin and eosin staining, magnification $\times 200$. 


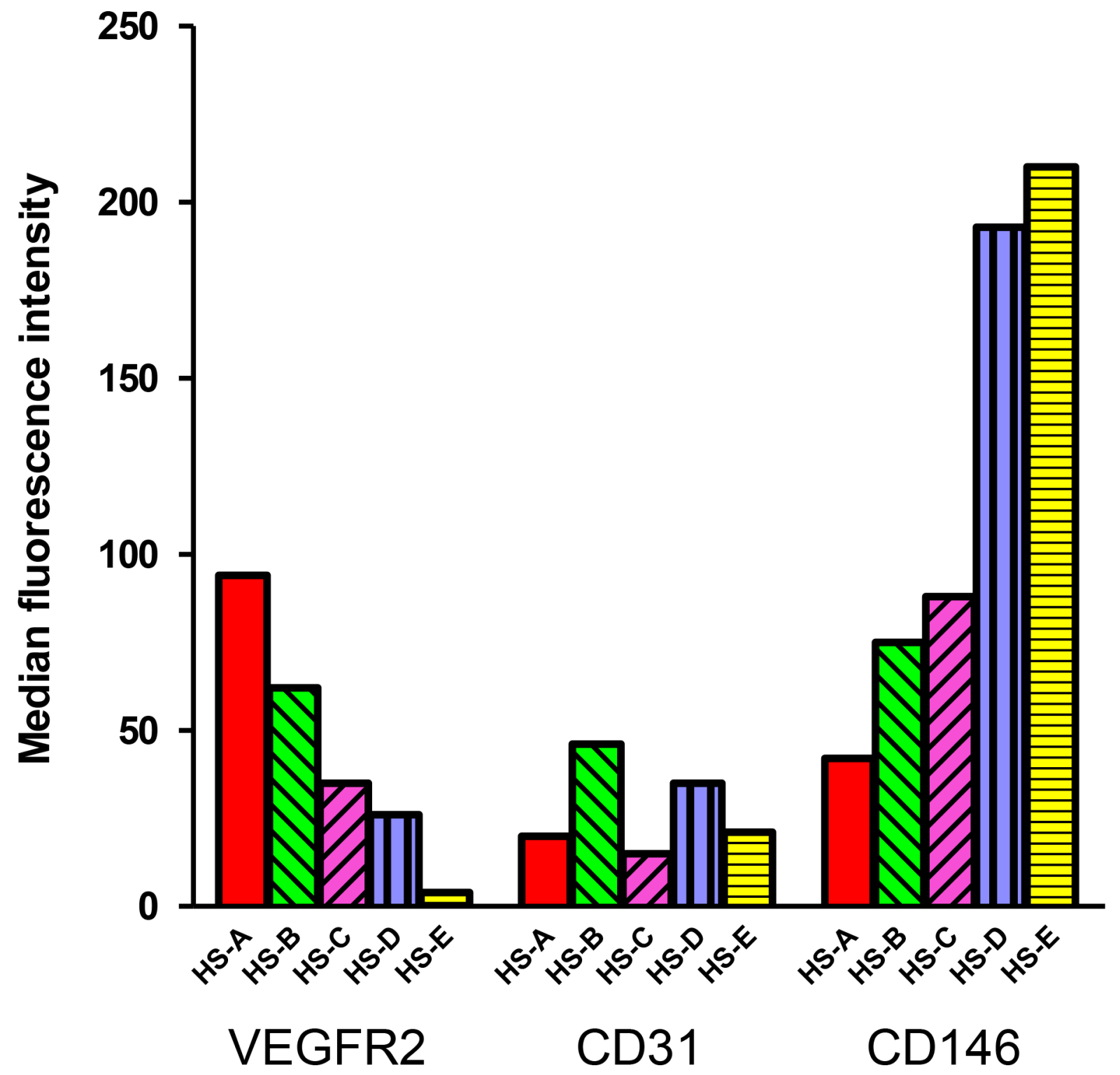

Figure 4: Expression of endothelial markers in hemangiosarcomas. Expression of VEGF-R2, CD31 and CD146 in five primary hemangiosarcomas determined by immunofluorescence and cytofluorometric analysis, after mechanical and enzymatical dissociation of the tumor. Bars represent the median fluorescence intensity of each marker in each different hemangiosarcoma.

generally much slower than in homozygotes (compare Fig. 2A and 7A). As in homozygotes, also in p53 heterozygous mice the general tumor load was similar in BALB-p53 $3^{+-}$and RGKO-p53 $3^{+-}$(median 2, range 1-6, and median 2, range $1-10$, respectively) but the proportion of mice with multiple tumor histotypes was significantly increased in RGKO-p53 $3^{+/}$mice (Fig. 5).

Lymphomas were found in about $20 \%$ of BALB-p53 $3^{+-}$mice, and again cross-breeding with RGKO mice prevented their onset, but the tumor spectrum of RGKO-p $53^{+/-}$mice showed only minor modifications (Fig. 7B). As in homozygotes, the incidence of hemangiosarcomas increased in $\mathrm{RGKO}-\mathrm{p} 53^{+/-}$mice in comparison to BALB-p53 $53^{+/-}$mice of both sexes.
Female RGKO-p53 ${ }^{+/-}$showed a distinctive increase, up to $20 \%$, in the incidence of osteosarcoma, which became the third most common tumor in these mice (Fig. 7B). Osteosarcomas (Fig. 3 D-F) mainly affected the limbs (90\% of cases) and gave rise to spontaneous metastatic dissemination, in particular to the lungs ( $25 \%$ of cases).

Tumor-free survival rates of BALB-p53 $3^{+-}$and RGKO-p $53^{+/-}$were similar, however tumor onset was slightly but significantly faster in immunodeficient RGKO-p53 $3^{+/-}$mice than in BALB-p53 $3^{+/-}$mice (Fig. 7A). Tumor-free survival curves of individual tumor histotypes showed that hemangiosarcoma-free survival and osteosarcoma-free survival were significantly different 


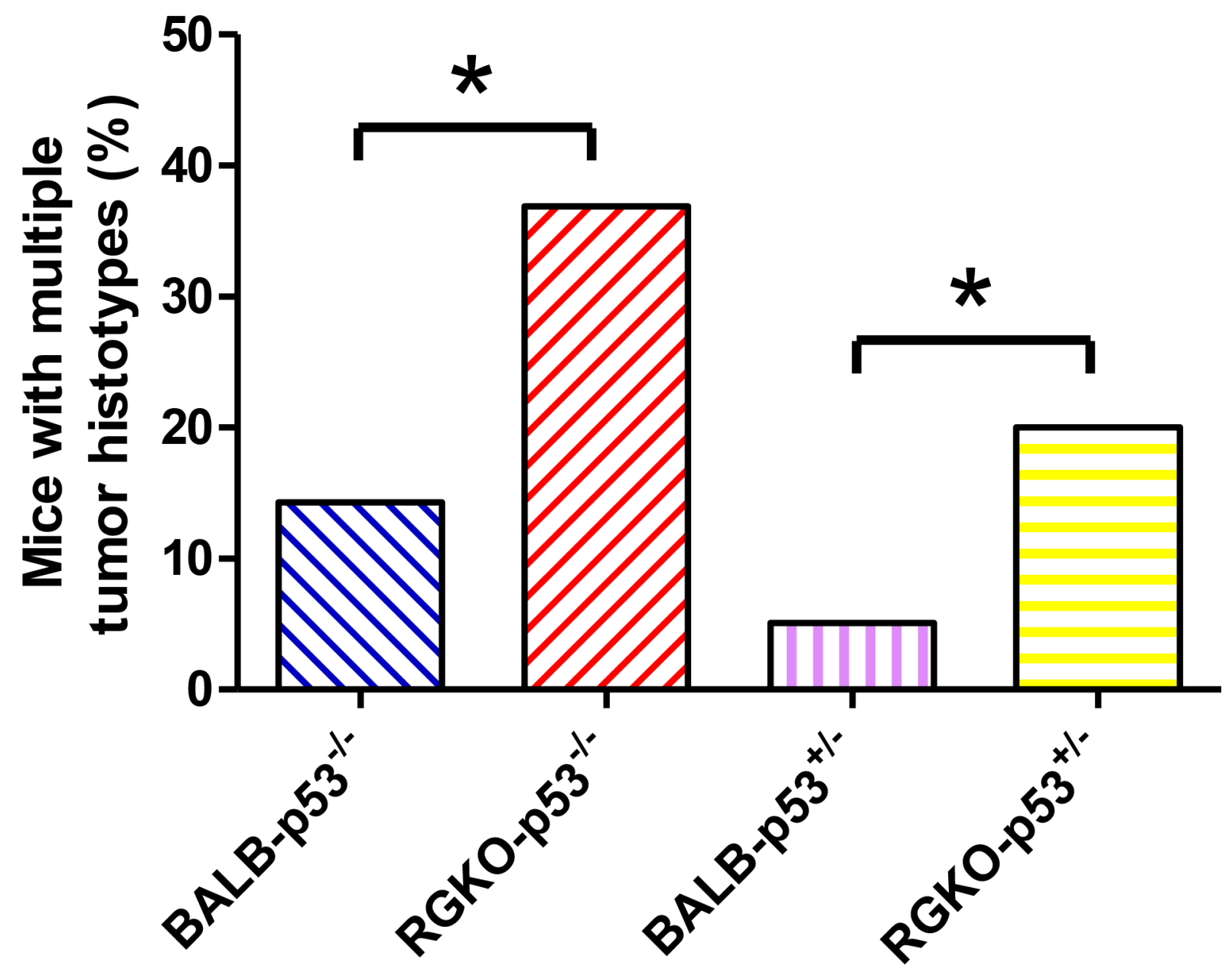

Figure 5: Mice bearing multiple tumor histotypes. The proportion of mice bearing multiple tumor histotypes was significantly higher in RGKO-p53 compared to BALB-p53 (*p $<0.05, \chi^{2}$ analysis).

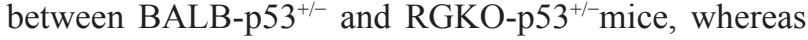
lymphoma-free survival did not differ significantly and soft tissue sarcoma-free and mammary carcinoma-free survival almost overlapped, possibly suggesting a (weak) immunological control in long-term tumor development mainly regarding sarcomas (Fig. 6B).

\section{Hemangiosarcoma and osteosarcoma cell lines}

To further investigate the nature of tumors arising in RGKO-p53 $3^{-/}$mice, we derived in vitro cultures and established stable cell lines from hemangiosarcomas and osteosarcomas. Hemangiosarcoma cell lines, which in vitro expressed typical endothelial markers, such as VEGF-R2, CD31 and CD146, were poorly tumorigenic, giving rise to local tumors only after very long latency times (Tab. 1). In contrast, osteosarcoma cell lines rapidly gave rise to ossified local tumors (Tab. 1). In both cases, growth in immunocompetent mice was less efficient and slower than in immunodeficient mice, thus indicating immune recognition of cells deriving from tumors arisen in immunodeficient hosts. Distant metastases to the lungs were found in a sizeable proportion ( $>40 \%$ ) of mice bearing local tumors, in particular in immunodeficient mice. Intravenous injections of tumor cells confirmed the faster growth and the higher malignancy of osteosarcoma cells (Tab. 2).

\section{Expression of p53 and p53-related tumor suppressor genes}

We analyzed the expression of p53 in normal tissues, tumors and cell lines obtained from mice carrying different $\mathrm{p} 53$ genotypes. As expected, $\mathrm{p} 53$ was absent in all samples from $\mathrm{p} 53^{-/-}$mice (Fig. 8). It is worth noting that osteosarcomas of $\mathrm{p} 53^{+/-}$mice retained $\mathrm{p} 53$ heterozygosity, which was instead lost in cell lines, a phenomenon known to occur also in human tumors [20].

We have recently shown that, in a different mouse model [21] sharing with the present ones the knockout of $\mathrm{p} 53$, various $\mathrm{p} 53$-related tumor suppressor genes were hyperexpressed [22], such as cyclin-dependent kinase inhibitor 1A (CDKN1A/p21Cip1), cyclindependent kinase inhibitors 2A (CDKN2A/p19Arf, $C D K N 2 A / p 16 \operatorname{Ink} 4 a)$ and cyclin-dependent kinase 

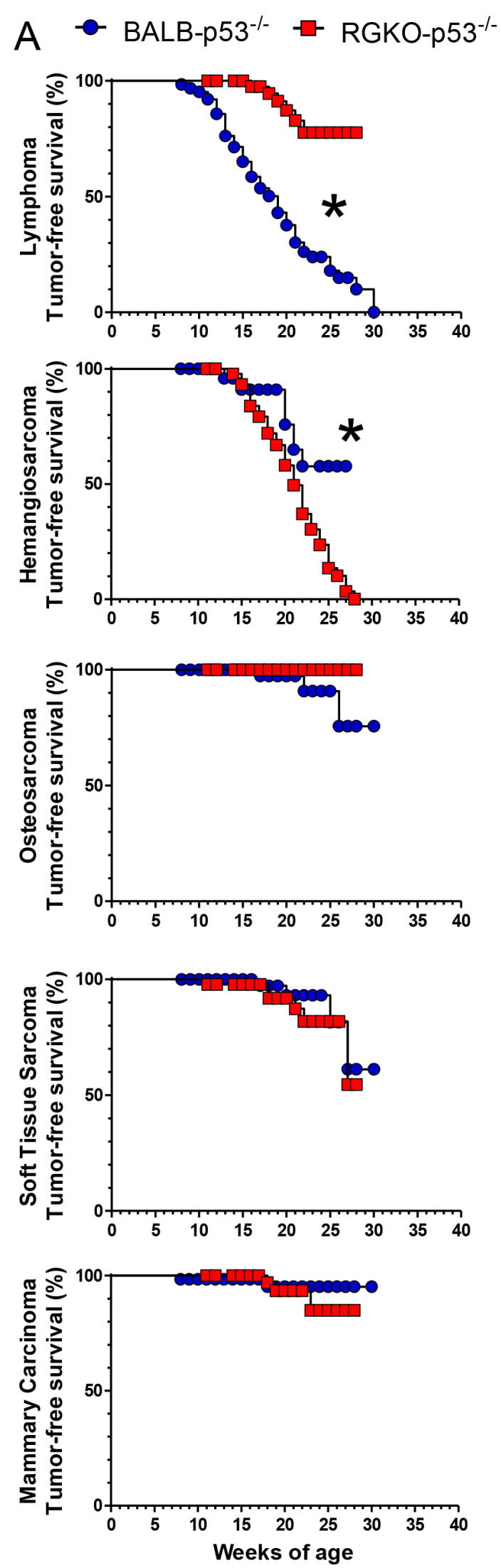

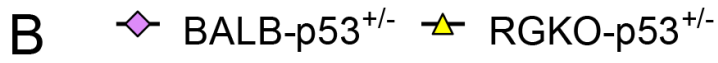
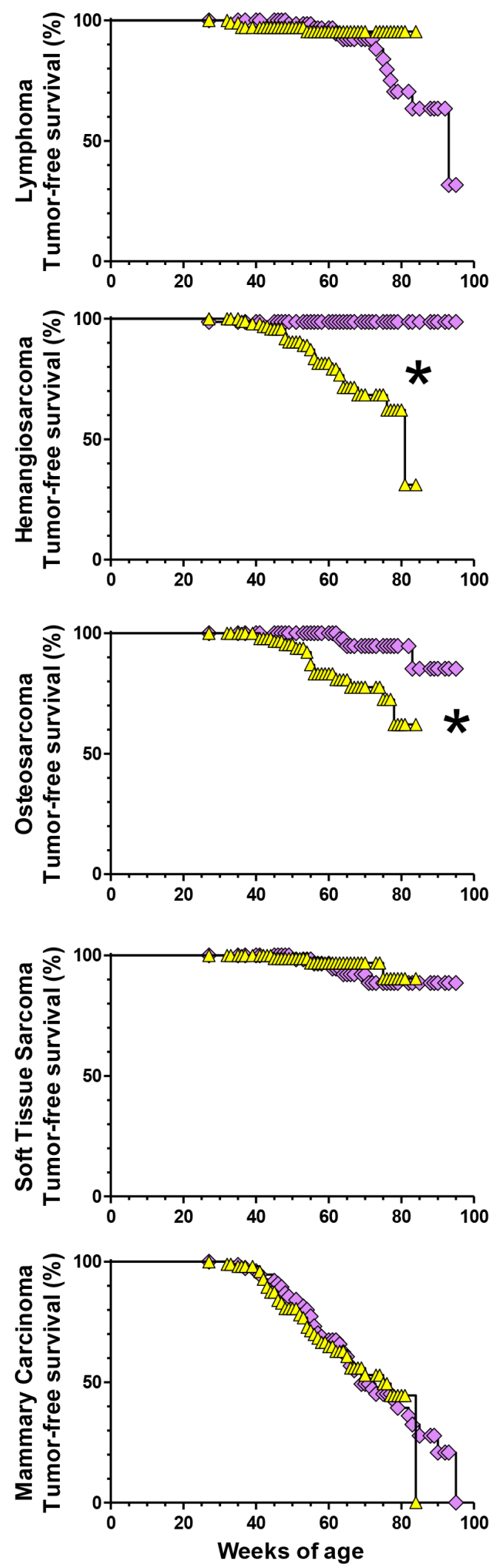

Figure 6: Tumor-free survival rate by individual tumor histotype of homozygous and heterozygous p53 knockout mice. Kaplan-Meier tumor-free survival curves of $\mathrm{p} 53^{--}$(A) and $\mathrm{p} 53^{+-}$(B) mice. Stars denote significant $(p<0.01)$ differences between BALB-p53 and RGKO-p53 mice by the logrank Mantel-Haenszel test. 
A

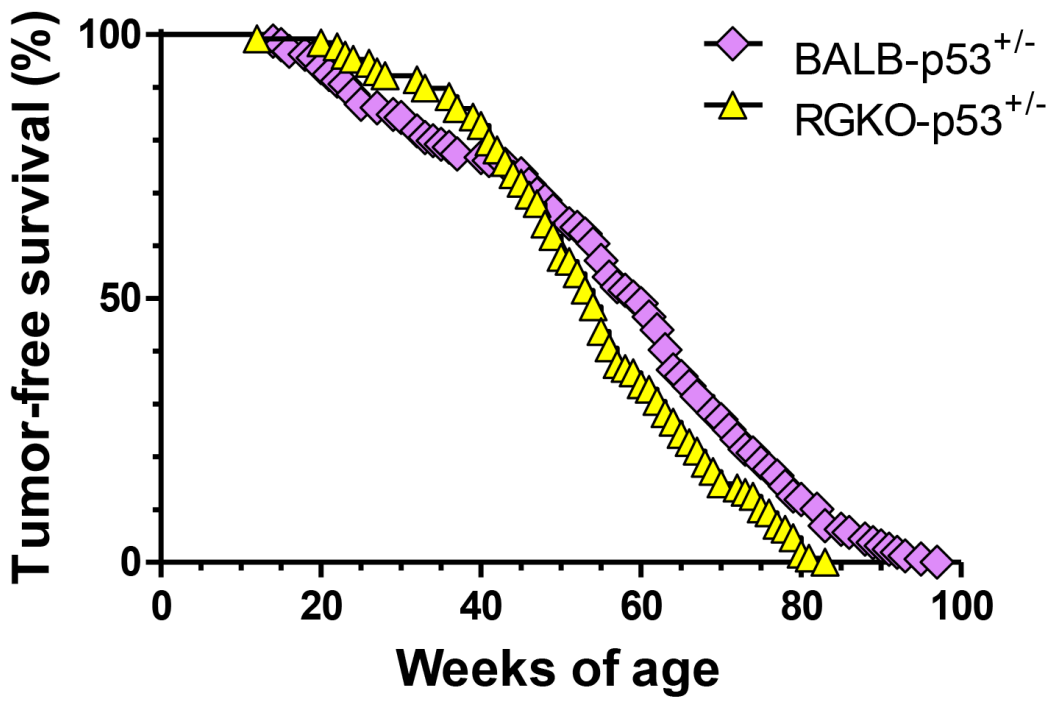

B

Lymphoma

II Hemangiosarcoma

$\square$ Soft tissue sarcoma

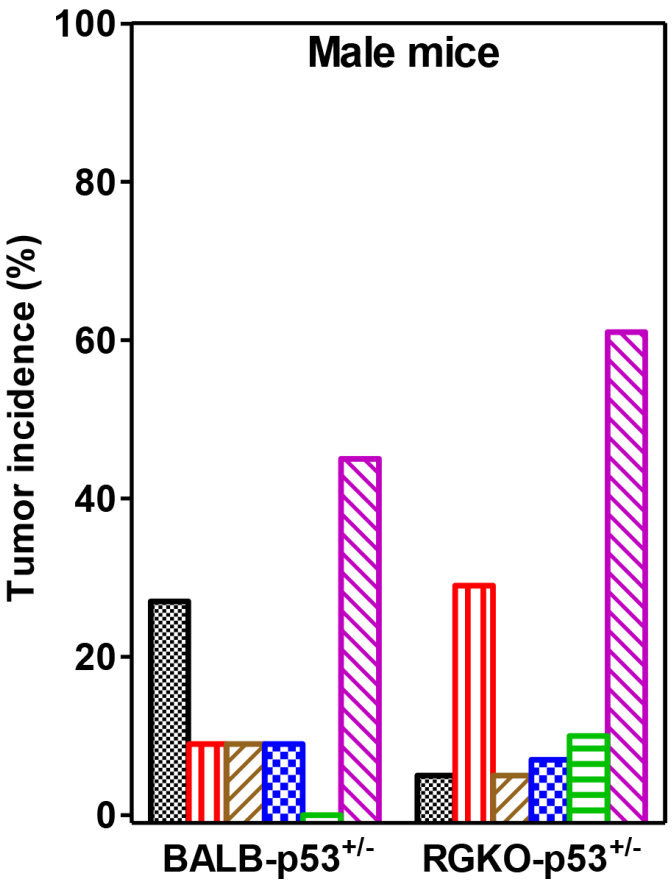

Q Osteosarcoma

Mammary carcinoma

$\mathbb{Q}$ Other

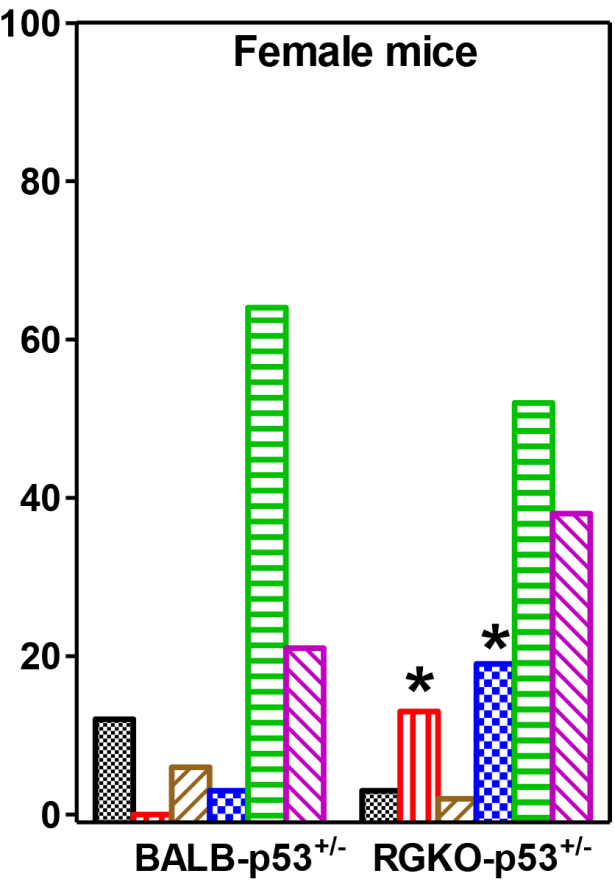

Figure 7: Tumor-free survival rate and tumor histotype incidence in heterozygous p53 mice. (A) Kaplan-Meier tumor-free survival curves of BALB-p53 ${ }^{+-}$(159 mice) and RGKO-p53 ${ }^{+/-}$mice (124 mice). Curves were significantly different by the logrank MantelHaenszel test, $p<0.01$. (B) Tumor histotype frequencies in BALB-p53 $3^{+/}$and RGKO-p53 $3^{+/}$mice. Global incidence of lymphomas was significantly lower in RGKO-p53 $3^{+-}$than in BALB-p53 $3^{+-}\left(p<0.05, \chi^{2}\right.$ analysis male BALB $n=11$, male RGKO $n=41$; female BALB $n=67$, female RGKO $n=64$ ). Hemangiosarcoma incidence was significantly higher in female RGKO-p53 ${ }^{+/}$compared to BALB-p53 ${ }^{+/}$ $\left({ }^{*} p<0.01, \chi^{2}\right.$ analysis), a similar trend was observed in males, and the cumulative incidence of hemangiosarcoma was significantly

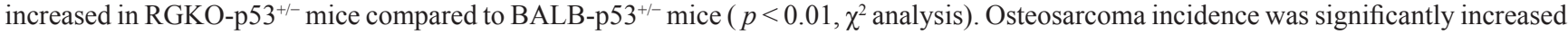
only in female RGKOp53 $3^{+-}$mice, $* p<0.01$ by $\chi^{2}$ analysis. The category "Other" included tumors of the genitourinary tract, adrenals, lungs, kidneys, salivary glands and liver, and its cumulative incidence in males and females was significantly higher in RGKO-p53 ${ }^{+/-}$than in BALB-p53 $3^{+-}$mice $\left(p<0.01, \chi^{2}\right.$ analysis). Mice showing multiple primary tumors were counted in each tumor type. 
Table 1: Tumorigenic ability of hemangiosarcoma and osteosarcoma cell lines in immunocompetent BALB/c and in immunodeficient RGKO mice.

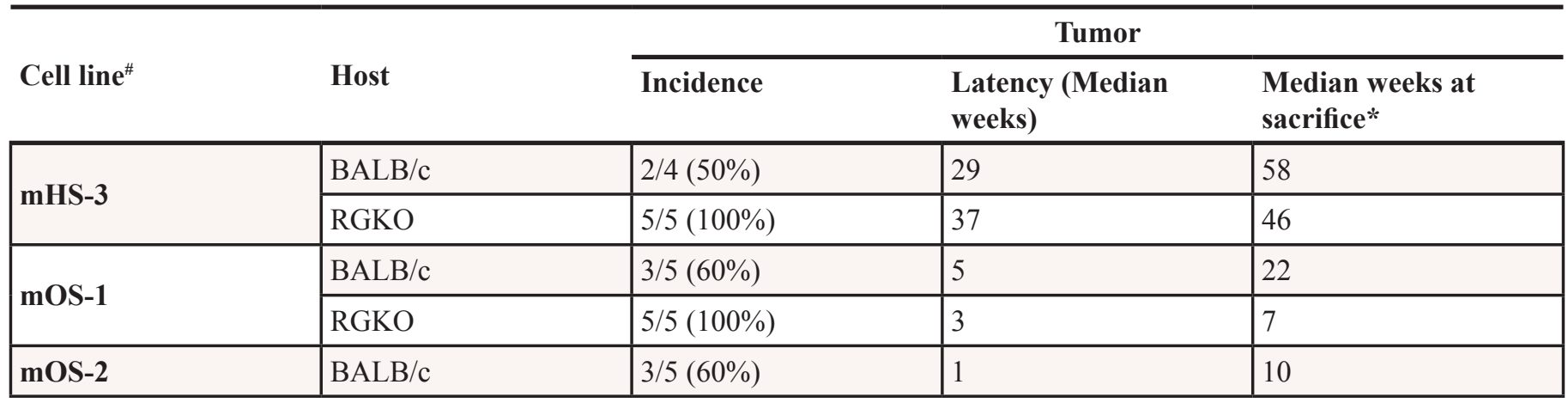

\#One hemangiosarcoma cell line (mHS-3) derived from RGKO-p53 ${ }^{-/}$mice and two osteosarcoma cell lines (mOS-1 and mOS-2) derived from RGKO-p53 $3^{+-}$mice were used. All mice were challenged with $10^{6}$ cells s.c.

*median weeks at sacrifice of tumor positive mice, when tumor volume reached $1.7 \mathrm{~cm}^{3}$.

Table 2: Metastatic ability of hemangiosarcoma and osteosarcoma cell lines in immunocompetent BALB/c and in immunodeficient RGKO mice.

\begin{tabular}{|c|c|c|c|c|c|c|}
\hline \multirow{2}{*}{ Cell line } & \multirow{2}{*}{ Host } & \multirow{2}{*}{$\begin{array}{l}\text { Number of cells } \\
\text { injected i.v. }\end{array}$} & \multirow{2}{*}{$\begin{array}{l}\text { Time to sacrifice(Median } \\
\text { weeks after treatment) }\end{array}$} & \multicolumn{3}{|c|}{ Lung metastases } \\
\hline & & & & Incidence & Median & Range \\
\hline \multirow{3}{*}{ mHS-3 } & \multirow{2}{*}{$\mathrm{BALB} / \mathrm{c}$} & $10^{5}$ & 59 & $2 / 4(50 \%)$ & 1 & $0-3$ \\
\hline & & $10^{6}$ & 59 & $5 / 5(100 \%)$ & 6 & $1->200$ \\
\hline & RGKO & $10^{5}$ & 59 & $1 / 3(33 \%)$ & 0 & $0-3$ \\
\hline \multirow{4}{*}{ mOS-1 } & \multirow{2}{*}{$\mathrm{BALB} / \mathrm{c}$} & $10^{5}$ & 58 & $3 / 3(100 \%)$ & 3 & $2-9$ \\
\hline & & $10^{6}$ & 17 & $3 / 3(100 \%)$ & $>200$ & $>200$ \\
\hline & \multirow{2}{*}{ RGKO } & $10^{5}$ & 31 & $3 / 3(100 \%)$ & 15 & $10-20$ \\
\hline & & $10^{6}$ & 17 & $3 / 3(100 \%)$ & $>200$ & $>200$ \\
\hline
\end{tabular}

inhibitor 2B $(C D K N 2 B / p 15 \operatorname{Ink} 4 b)$ [23-28]. Therefore we studied the expression of these genes in tumors and cell lines of RGKO-p53 ${ }^{-/-}$and RGKO-p53 ${ }^{+/-}$mice. We found that their expression was significantly enhanced in comparison to normal tissues of mesenchymal origin with different $\mathrm{p} 53$ status (p53 $\left.3^{+/+},{ }^{+/},{ }^{-/-}\right)$, thus confirming that the impairment of p53 causes an increase in the expression of related tumor suppressor genes (Fig. 8).

\section{DISCUSSION}

Carcinogenesis in p53 knockout mice recapitulates the natural history of tumor onset in humans, starting with lymphoid malignancies, followed by sarcomas, then by carcinomas. However, in p53 knockout mice, the high prevalence and fast growth of lymphomas obscured all other tumor histotypes.
Thank to the fact that life without mature lymphocytes is possible, if the host is not exposed to deadly infections, we could strongly reduce the onset of lymphomas in p53 knockout mice by crossing them with alymphocytic Rag2 $2^{-/-} ; 112 \mathrm{rg}^{-/-}$mice. This revealed a tumor landscape dominated by soft tissue sarcomas, in particular of vascular origin. It is interesting to note that the global incidence of carcinomas remained far below the incidence of sarcomas, thus suggesting that, as sarcomas were masked by lymphomas, now carcinomas are masked by sarcomas. If it were possible to genetically delete the mesenchymal cells that give rise to sarcomas, as we did with lymphoma precursors, all mice would probably develop carcinomas at a later age. It is worth mentioning that in p53 knockout mice a shift from lymphomas to sarcomas, and an increase in survival was obtained also by treatment with rapamycin the inhibitor of mTOR (mammalian Target Of Rapanycin) [29]. The activity of 
Normal, p53+/+

$\Delta$ Normal, p53+/-

区 Normal, p53-/-

区 $\mathrm{HS}=$ Hemangiosarcomas (p53- /-)

HS cells = Hemangiosarcoma cell lines (p53-/-)
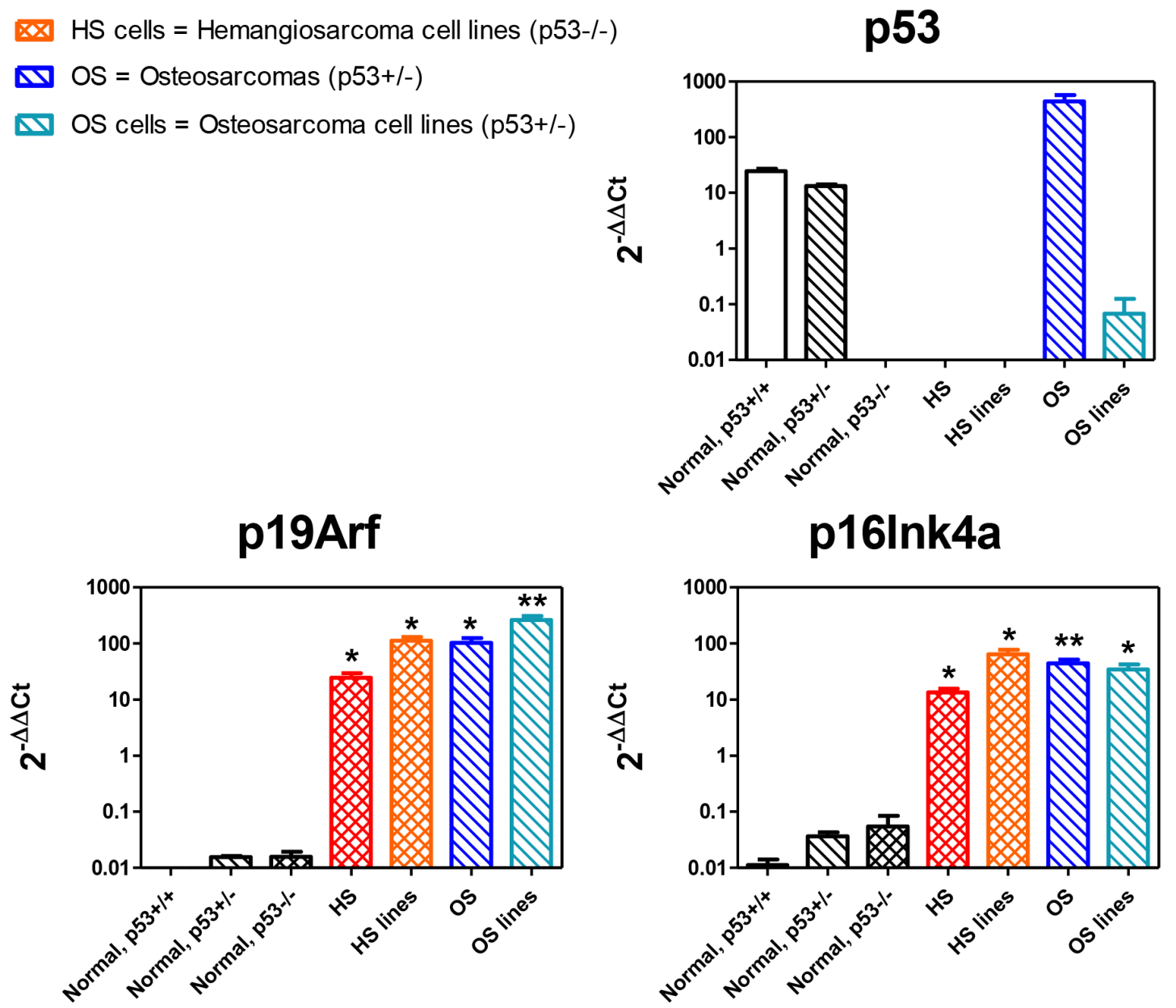

p16Ink4a

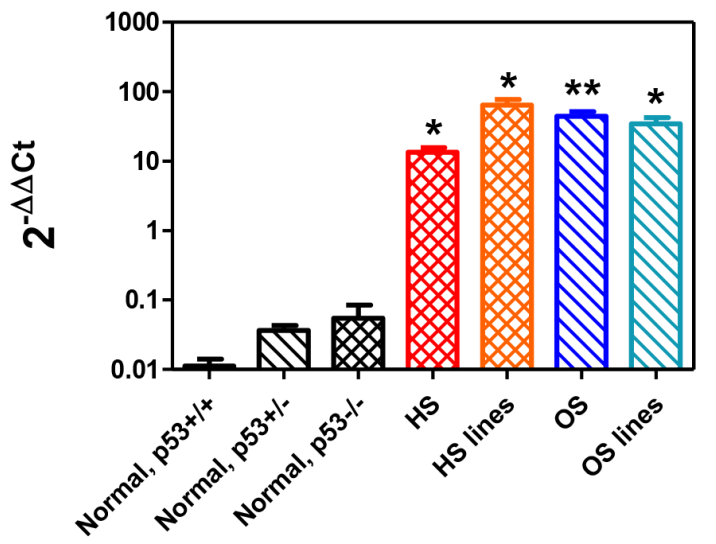

p15Ink4b

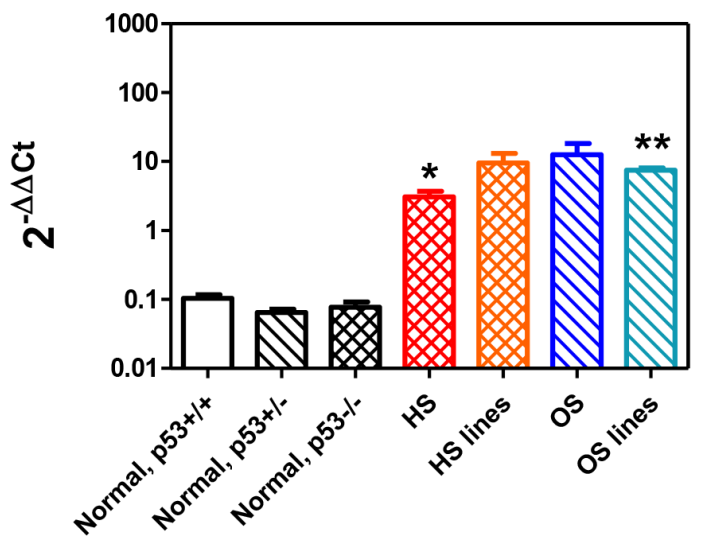

\section{p21Cip1}

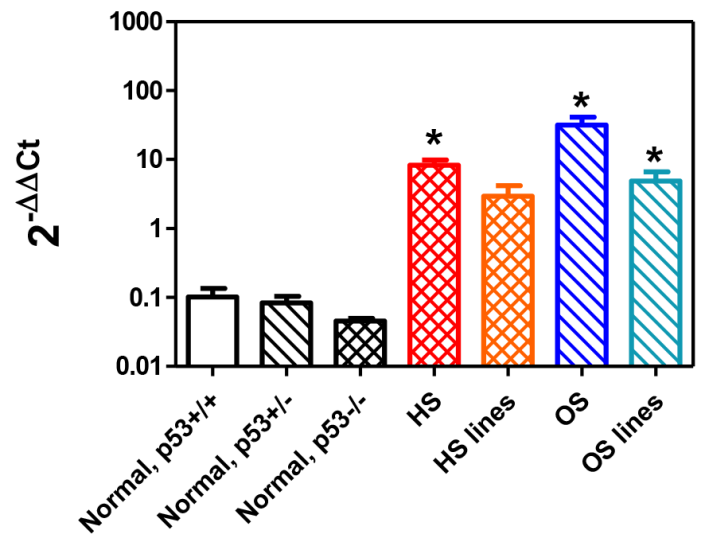

Figure 8: Expression of p53-related genes. Each panel represents the expression of the indicated gene in hemangiosarcomas (from

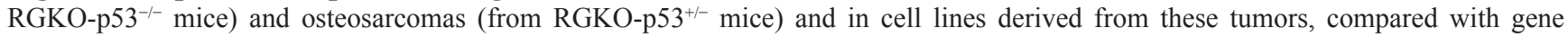
expression in normal cells of mesenchymal origin (quadriceps muscle) of $\mathrm{p} 53^{+/+}, \mathrm{p} 53^{+/-}$and $\mathrm{p} 53^{-/ /}$carrying a different $\mathrm{p} 53$ status. Each bar in a panel represents the mean \pm SEM gene expression level relative to the average of all samples (3-5 samples from different animals), normalized over GAPDH as endogenous reference gene. Statistical comparison between normal and tumor samples of $\mathrm{p} 53^{-/}$and $\mathrm{p} 53^{+/-}$ genotypes, ${ }^{*} p<0.05,{ }^{* *} p<0.01$ Student's $t$ test. 
the mTOR pathway, usually inhibited by $\mathrm{p} 53$, seems to be increased in some tissues of $\mathrm{p} 53^{-/-}$mice with a tendency to elevated IGF-1 levels, but the effects of absence of p53 can be partially attenuated by rapamycin, leading to changes in tumor spectrum [29, 30].

The tumor spectrum of $\mathrm{p} 53^{+/-}$heterozygotes is completely different from that of $\mathrm{p} 53^{-1-}$ homozygotes. Firstly, tumors arise much later in the life of heterozygotes. As these tumors usually show loss of heterozygosity at p53, the longer latency can be equaled to the time required for the loss of the wild-type p53 allele. Secondly, carcinomas dominate the tumor spectrum of heterozygotes. There could be several explanations for this fact, however the simplest one connects long latency with tumor histotype: loss of p53 heterozygosity occurs when mesenchymal cell populations are mostly quiescent, after the burst of proliferation required for growth to adult size, thus neoplastic transformation to sarcoma becomes relatively rare. For what concerns the tumor spectrum modifications introduced by the alymphocytic $\mathrm{Rag}^{-/-} ; \mathrm{Il}_{2} \mathrm{rg}^{-/-}$genotype, as in $\mathrm{p} 53^{-/-}$mice, also in $\mathrm{p} 53^{+/-}$ mice, this resulted in a reduction of lymphomas in favor of sarcomas.

The sizeable incidence of osteosarcomas in female RGKO-p53 $3^{+-}$mice makes an interesting model system for the study of bone tumors. It is worth noting that epidemiological studies of human osteosarcoma show a typical bimodal age distribution of tumor onset, with a first peak in early adolescence and a second peak in adults over the age of 65 . Osteosarcoma among the elderly is frequently related to Paget's disease or represents a second malignancy, in some instances caused by previous radiation therapy for the first tumor. The incidence of osteosarcoma generally is higher in males than in females, but in the case of osteosarcoma as a second malignancy some studies reported a slightly higher frequency in females [31]. The increased incidence of osteosarcoma in immunodeficient female $\mathrm{p} 53^{+/-}$mice could reflect the higher incidence of osteosarcoma as second tumor in women and, when compared to the lower incidence in female immunocompetent $\mathrm{p} 53^{+/-}$mice, could suggest a role for the immune response.

RGKO mice lack adaptive immune responses and innate responses are severely impaired, not only because they lack NK cells, but also because all the cytokines secreted by the various lymphoid subpopulations are absent. The fact that the profound immune deficiency of RGKO mice caused only minor variations in tumor latency of p53 knockout mice is a testament to the potency of the carcinogenic risk (or better, carcinogenic certainty) triggered by p53 alterations. In fact, the only detectable variations ascribable to the lack of immune surveillance were the slightly faster onset of tumors, in particular sarcomas, in RGKO-p53 ${ }^{+/}$mice and the slower growth of tumor cells derived from the same tumors in immunocompetent versus immunodeficient hosts.
The latter result could be attributed to the immunogenicity of tumors arising in the absence of immunoediting, i.e. the negative selection of immunogenic cell variants actuated by the immune system in immunocompetent mice [32].

RGKO-p53 $3^{-/-}$mice are a novel model system for the preclinical development of targeted therapies of human cancer with p53 alterations, which represent a prevalent molecular alteration of human tumors in need of novel targeted therapeutic approaches. A challenging set of new molecular targets can derive directly from the lack of p53, which frequently results in the derangement both of upstream p53 regulators and of downstream p53-regulated genes [22, 33-39]. In fact, various tumor suppressor genes, such as p21Cip1, p16Ink4a, p15Ink4b and p19Arf were up-regulated in sarcomas of RGKO-p53 mice, thus offering novel opportunities for the development of synthetic lethal therapeutic approaches.

In conclusion, we have shown that it is possible to modify the spectrum of tumors of p53 knockout mice which, in the absence of lymphocytes, develop a variety of solid tumors, in particular soft tissue sarcomas and osteosarcomas. The alymphocytic p53 knockout mice are a novel model system for studies of sarcoma development and for preclinical studies of targeted therapies.

\section{MATERIALS AND METHODS}

\section{Ethics statement}

All animal experiments were performed according European directive 2010/63/UE and Italian law (DL 26/2014). Experimental protocols were reviewed and approved by the Institutional Animal Care and Use Committee ("Comitato Etico Scientifico per la Sperimentazione Animale") of the University of Bologna, and forwarded to the Italian Ministry of Health with letter 4783-X/10 (Responsible Researcher Prof. P. Nanni).

\section{Mice}

BALB/c p53 ${ }^{+/}$mice (BALB/cJ-Trp53tm1Tyj, originally obtained from The Jackson Laboratory, Bar Harbor, MI) have one p53 allele inactivated by the insertion of a neomycin resistance cassette in the region spanning exons 2 to 6 [5]. $\mathrm{Rag}^{-/-} ; \mathrm{Il}^{2} \mathrm{rg}^{-/-}$breeders were kindly given by Drs. T. Nomura and M. Ito of the Central Institute for Experimental Animals (Kawasaki, Japan) $[40,41]$. Mice were bred in our animal facilities under sterile conditions. BALB-p53 $3^{+/}$mice were crossed with BALB Rag2 $2^{--} ; \mathrm{Il}_{2} \mathrm{rg}^{-/-}$and the offspring were genotyped by PCR analysis of genomic DNA (see below for PCR conditions and primers). Selected progeny was used for subsequent crossings. Starting with the F2 generation, mice carrying genotypes of interest were weekly inspected for early signs of tumor onset (dyspnea, weight loss or suffering) in addition to meticulous palpation of limbs, 
mammary glands and peritoneum internal organs. Mice were sacrificed according to the criteria for humane endpoints approved by the Institutional Animal Care and Use Committee of the University of Bologna. At sacrifice, an accurate necropsy was performed. Brain, lung, heart, liver, adrenals, kidneys, spleen and lymph nodes, genitourinary tract, salivary glands, subcutis, muscles, mammary glands and limbs were macroscopically inspected and samples were collected of all visible tumors. Part of each tumor was fixed in $10 \%$ formalin, when necessary decalcified, and embedded in paraffin. The remaining tumor was divided into small samples and snap frozen. Two-three-micrometer paraffin sections were stained with hematoxylin and eosin and evaluated by an experienced pathologist.

\section{Cell lines, tumorigenic and metastatic potential}

Osteosarcoma and hemangiosarcoma cell cultures were established from mechanically dissociated tumors. Hemangiosarcomas were cultured in DMEM (Dulbecco's Modified Eagle Medium) $+20 \%$ fetal bovine serum (FBS); osteosarcomas were cultured in IMDM (Iscove's Modified Dulbecco's Medium) $+10 \%$ FBS. All cells were maintained at $37^{\circ} \mathrm{C}$ in a $7 \% \mathrm{CO}_{2}$ atmosphere. Tumor samples and cell lines were analysed by immunofluorescence and cytofluorometric analysis using the following anti-mouse antibodies: VEGF-R2 (clone Avas12 $\alpha 1$ ), CD31 (clone MEC 13.3), CD146 (clone ME-9F1), CD45R/B220 (clone RA3-6B2), CD3 (clone 145-2C11), CD4 (clone GK1.5), CD8 (clone 53-6.7) all from Pharmingen BD Biosciences. To assess tumorigenicity and metastatic ability, cells were injected subcutaneuosly or intravenously in syngeneic immunocompetent or immunodeficient hosts. Mice were inspected weekly for tumor growth. Tumor volumes were calculated as $\pi[\sqrt{ }(a \times b)]^{3} / 6$ where $a=$ maximal tumor diameter and $b=$ major tumor diameter perpendicular to $a$. After sacrifice, an accurate necropsy was performed, then lungs were perfused with black India ink to outline metastases and fixed in modified Fekete's solution. Lung metastases were counted under a dissection microscope.

\section{Genotyping and real-time polymerase chain reaction}

DNA for genotyping was isolated by digestion of tail tissue in a buffer containing proteinase K. To distinguish between the wild-type and mutant allele, two sets of primers were used for each gene: Wild-type $I l 2 \mathrm{rg}$ gene, forward CTG CTC AGA ATG CCT CCAATT CC, reverse GAT CCA GAT TGC CAA GGT GAG TAG; mutated IL2rg gene, same forward primer, reverse CCT GCG TGC AAT CCA TCT TGT TCA AT (neo cassette) [42]. Wild-type $R A G 2$ gene, forward GGG AGG ACA CTC
ACT TGC CAG TA, reverse AGT CAC TCT ACC TCT GAG GAC TGA; mutated RAG2 gene, same reverse primer and forward CGG CCG GAG AAC CTG CGT GCA A (neo cassette) [43, 44]. Wild-Type Trp53 gene, forward CCC GAG TAT CTG GAA GAC AG, reverse TAC TTG GCG GCT GGA TA; mutated Trp53 gene same reverse primer and forward CTT GGG TGG AGA GGC TAT TC (neo cassette).

Gene expression was evaluated by quantitative real-time PCR using SYBR Green PCR Master Mix reagents (Applera, Milan, Italy) and analyzed by means of a Thermal Cycler Gene Amp 5700 Sequence Detection System (Applied Biosystem, Applera, Milano) using the following primer pairs: mouse GAPDH (forward, GCT CAC TGG CAT GGC CTT C; reverse, CGG TTC ATA CTA CTG TAG TTC TTC C); TrP53 (forward, CCC GAG TAT CTG GAA GAC AG; reverse, TAC TTG GCG GCT GGA TA); CDKN2A/p19Arf (forward, GCT CTG GCT TTC GTG AAC ATG; reverse, CTA CTA CCC GTT GCA AGT GC); CDKN2A/p16Ink4a (forward, ACT CTT TCG GTC GTA CCC CG; reverse, CTA CTA CCC GTT GCA AGT GC); $C D K N 2 B / p 15 \operatorname{Ink} 4 b$ (forward, CCA ATC CAG GTC ATG ATG ATG G; reverse, GGT GCC TCG TCT TGG GTT); CDKN1A/p21Cip1 (forward, GGA ACA TCT CAG GGC CGA A; reverse, TCT TTT GGG ACT TCA CGG GT).

\section{ACKNOWLEDGEMENTS}

The authors dedicate this work to the memory of Marco Alberghini, friend and colleague who greatly contributed to the histological studies reported here. Special thanks for his technical assistance to Dr. Stefano Zagnoni who was in receipt of a fellowship from Associazione Onlus "Il Pensatore: Matteo Amitrano".

This work was supported by grants from: Italian Association for Cancer Research (AIRC), Milan, Italy (project no. 10353 to PLL); the Department of Experimental Pathology, University of Bologna (Pallotti funds); and the Italian Ministry for University and Research (PRIN 2009 to PLL). Fellowships: Italian Foundation for Cancer Research, Milan, Italy (to VG); University of Bologna (to MLI, AP, RL and MDO). The authors declare no conflict of interest.

\section{REFERENCES}

1. Levine AJ, Oren M. The first 30 years of p53: growing ever more complex. Nat Rev Cancer. 2009; 9:749-758.

2. Vousden KH, Prives C. Blinded by the Light: The Growing Complexity of p53. Cell. 2009; 137:413-431.

3. Donehower LA, Harvey M, Slagle BL, McArthur MJ, Montgomery CA, Jr., Butel JS, Bradley A. Mice deficient for p53 are developmentally normal but susceptible to spontaneous tumours. Nature. 1992; 356:215-221. 
4. Donehower LA, Lozano G. 20 years studying p53 functions in genetically engineered mice. Nat Rev Cancer. 2009; 9:831-841.

5. Kuperwasser C, Hurlbut GD, Kittrell FS, Dickinson ES, Laucirica R, Medina D, Naber SP, Jerry DJ. Development of spontaneous mammary tumors in BALB/c p53 heterozygous mice. A model for Li-Fraumeni syndrome. Am J Pathol. 2000; 157:2151-2159.

6. Liu G, McDonnell TJ, Montes de Oca LR, Kapoor M, Mims B, El-Naggar AK, Lozano G. High metastatic potential in mice inheriting a targeted p53 missense mutation. Proc Natl Acad Sci U S A. 2000; 97:4174-4179.

7. Olivier M, Hollstein M, Hainaut P. TP53 mutations in human cancers: origins, consequences, and clinical use. Cold Spring Harb Perspect Biol. 2010; 2:a001008.

8. Oren M, Rotter V. Mutant p53 gain-of-function in cancer. Cold Spring Harb Perspect Biol. 2010; 2:a001107.

9. Muller PA, Vousden KH. Mutant p53 in cancer: new functions and therapeutic opportunities. Cancer Cell. 2014; 25:304-317.

10. Cohen SM, Storer RD, Criswell KA, Doerrer NG, Dellarco VL, Pegg DG, Wojcinski ZW, Malarkey DE, Jacobs AC, Klaunig JE, Swenberg JA, Cook JC. Hemangiosarcoma in rodents: mode-of-action evaluation and human relevance. Toxicol Sci. 2009; 111:4-18.

11. Jones KB. Osteosarcomagenesis: modeling cancer initiation in the mouse. Sarcoma. 2011; 2011:694136.

12. Yang J, Kantrow S, Sai J, Hawkins OE, Boothby M, Ayers GD, Young ED, Demicco EG, Lazar AJ, Lev D, Richmond A. INK4a/ARF [corrected] inactivation with activation of the NF-kappaB/IL-6 pathway is sufficient to drive the development and growth of angiosarcoma. Cancer Res. 2012; 72:4682-4695.

13. Wen VW, MacKenzie KL. Modeling human endothelial cell transformation in vascular neoplasias. Dis Model Mech. 2013; 6:1066-1079.

14. Guijarro MV, Ghivizzani SC, Gibbs CP. Animal models in osteosarcoma. Front Oncol. 2014; 4:189.

15. Traggiai E, Chicha L, Mazzucchelli L, Bronz L, Piffaretti JC, Lanzavecchia A, Manz MG. Development of a human adaptive immune system in cord blood celltransplanted mice. Science. 2004; 304:104-107.

16. Egerton M, Scollay R, Shortman K. Kinetics of mature T-cell development in the thymus. Proc Natl Acad Sci U S A. 1990; 87:2579-2582.

17. Jiang D, Lenardo MJ, Zuniga-Pflucker JC. p53 prevents maturation to the $\mathrm{CD} 4+\mathrm{CD} 8+$ stage of thymocyte differentiation in the absence of $\mathrm{T}$ cell receptor rearrangement. J Exp Med. 1996; 183:1923-1928.

18. Bassing CH, Ranganath S, Murphy M, Savic V, Gleason M, Alt FW. Aberrant V(D)J recombination is not required for rapid development of $\mathrm{H} 2 \mathrm{ax} / \mathrm{p} 53$-deficient thymic lymphomas with clonal translocations. Blood. 2008; 111:2163-2169.

19. Martins VC, Busch K, Juraeva D, Blum C, Ludwig C, Rasche V, Lasitschka F, Mastitsky SE, Brors B, Hielscher T, Fehling HJ, Rodewald HR. Cell competition is a tumour suppressor mechanism in the thymus. Nature. 2014; 509:465-470.

20. De Giovanni C, Landuzzi L, Nicoletti G, Lollini PL, Nanni P. Molecular and cellular biology of rhabdomyosarcoma. Future Oncol. 2009; 5:1449-1475.

21. Nanni P, Nicoletti G, De Giovanni C, Croci S, Astolfi A, Landuzzi L, Di Carlo E, Iezzi M, Musiani P, Lollini PL. Development of rhabdomyosarcoma in HER-2/neu transgenic p53 mutant mice. Cancer Res. 2003; 63:2728-2732.

22. Ianzano ML, Croci S, Nicoletti G, Palladini A, Landuzzi L, Grosso V, Ranieri D, Dall'Ora M, Santeramo I, Urbini M, De Giovanni C, Lollini PL, Nanni P. Tumor suppressor genes promote rhabdomyosarcoma progression in p53 heterozygous, HER-2/neu transgenic mice. Oncotarget. 2014; 5:108-119.

23. Jung YS, Qian Y, Chen X. Examination of the expanding pathways for the regulation of $\mathrm{p} 21$ expression and activity. Cell Signal. 2010; 22:1003-1012.

24. Martin-Caballero J, Flores JM, Garcia-Palencia P, Serrano M. Tumor susceptibility of p21(Waf1/Cip1)deficient mice. Cancer Res. 2001; 61:6234-6238.

25. Ozenne P, Eymin B, Brambilla E, Gazzeri S. The ARF tumor suppressor: structure, functions and status in cancer. Int J Cancer. 2010; 127:2239-2247.

26. Serrano M, Lee H, Chin L, Cordon-Cardo C, Beach D, DePinho RA. Role of the INK4a locus in tumor suppression and cell mortality. Cell. 1996; 85:27-37.

27. Sharpless NE, Bardeesy N, Lee KH, Carrasco D, Castrillon DH, Aguirre AJ, Wu EA, Horner JW, DePinho RA. Loss of p16Ink4a with retention of p19Arf predisposes mice to tumorigenesis. Nature. 2001; 413:86-91.

28. Sharpless NE, Ramsey MR, Balasubramanian P, Castrillon DH, DePinho RA. The differential impact of p16(INK4a) or p19(ARF) deficiency on cell growth and tumorigenesis. Oncogene. 2004; 23:379-385.

29. Comas M, Toshkov I, Kuropatwinski KK, Chernova OB, Polinsky A, Blagosklonny MV, Gudkov AV, Antoch MP. New nanoformulation of rapamycin Rapatar extends lifespan in homozygous p53-/- mice by delaying carcinogenesis. Aging (Albany NY). 2012; 4:715-722.

30. Leontieva OV, Novototskaya LR, Paszkiewicz GM, Komarova EA, Gudkov AV, Blagosklonny MV. Dysregulation of the mTOR pathway in $\mathrm{p} 53$-deficient mice. Cancer Biol Ther. 2013; 14:1182-1188.

31. Mirabello L, Troisi RJ, Savage SA. Osteosarcoma incidence and survival rates from 1973 to 2004: data from the 
Surveillance, Epidemiology, and End Results Program. Cancer. 2009; 115:1531-1543.

32. Mittal D, Gubin MM, Schreiber RD, Smyth MJ. New insights into cancer immunoediting and its three component phases-elimination, equilibrium and escape. Curr Opin Immunol. 2014; 27:16-25.

33. Menendez D, Inga A, Resnick MA. The expanding universe of p53 targets. Nat Rev Cancer. 2009; 9:724-737.

34. Humbey O, Pimkina J, Zilfou JT, Jarnik M, DominguezBrauer C, Burgess DJ, Eischen CM, Murphy ME. The ARF tumor suppressor can promote the progression of some tumors. Cancer Res. 2008; 68:9608-9613.

35. De la Cueva E, Garcia-Cao I, Herranz M, Lopez P, GarciaPalencia P, Flores JM, Serrano M, Fernandez-Piqueras J, Martin-Caballero J. Tumorigenic activity of p21Waf1/Cip1 in thymic lymphoma. Oncogene. 2006; 25:4128-4132.

36. Romagosa C, Simonetti S, Lopez-Vicente L, Mazo A, Lleonart ME, Castellvi J, Cajal S. p16(Ink4a) overexpression in cancer: a tumor suppressor gene associated with senescence and high-grade tumors. Oncogene. 2011; 30:2087-2097.

37. Sharpless NE. Ink4a/Arf links senescence and aging. Exp Gerontol. 2004; 39:1751-1759.

38. Sharpless NE. INK4a/ARF: a multifunctional tumor suppressor locus. Mutat Res. 2005; 576:22-38.

39. Ivanchuk SM, Mondal S, Dirks PB, Rutka JT. The INK4A/ ARF locus: role in cell cycle control and apoptosis and implications for glioma growth. J Neurooncol. 2001; 51:219-229.
40. Nanni P, Nicoletti G, Landuzzi L, Croci S, Murgo A, Palladini A, Antognoli A, Ianzano ML, Stivani V, Grosso V, Maira SM, Garcia-Echeverria C, Scotlandi K, et al. High metastatic efficiency of human sarcoma cells in Rag2/ gammac double knockout mice provides a powerful test system for antimetastatic targeted therapy. Eur J Cancer. 2010; 46:659-668.

41. Nanni P, Nicoletti G, Palladini A, Croci S, Murgo A, Ianzano ML, Grosso V, Stivani V, Antognoli A, Lamolinara A, Landuzzi L, Di Tomaso E, Iezzi M, et al. Multiorgan metastasis of human HER-2+ breast cancer in Rag2-/-;I12rg-/- mice and treatment with PI3K inhibitor. PLoS One. 2012; 7:e39626.

42. Ito M, Hiramatsu H, Kobayashi K, Suzue K, Kawahata M, Hioki K, Ueyama Y, Koyanagi Y, Sugamura K, Tsuji K, Heike T, Nakahata T. NOD/SCID/gamma(c)(null) mouse: an excellent recipient mouse model for engraftment of human cells. Blood. 2002; 100:3175-3182.

43. Colucci F, Soudais C, Rosmaraki E, Vanes L, Tybulewicz VL, Di Santo JP. Dissecting NK cell development using a novel alymphoid mouse model: investigating the role of the c-abl proto-oncogene in murine NK cell differentiation. J Immunol. 1999; 162:2761-2765.

44. Goldman JP, Blundell MP, Lopes L, Kinnon C, Di Santo JP, Thrasher AJ. Enhanced human cell engraftment in mice deficient in RAG2 and the common cytokine receptor gamma chain. Br J Haematol. 1998; 103:335-342. 